Proceeding Paper

\title{
Solar Powered Resonant Inverter Fed a High Voltage DC Power Supply ${ }^{\dagger}$
}

\author{
Muhammad Ajmal *(D), Shahid Iqbal and Arslan Arif
}

check for

updates

Citation: Ajmal, M.; Iqbal, S.; Arif, A. Solar Powered Resonant Inverter Fed a High Voltage DC Power Supply. Eng. Proc. 2021, 12, 70. https:// doi.org/10.3390/engproc2021012070

Academic Editor: M. Jehanzeb Irshad

Published: 6 January 2022

Publisher's Note: MDPI stays neutral with regard to jurisdictional claims in published maps and institutional affiliations.

Copyright: (C) 2022 by the authors. Licensee MDPI, Basel, Switzerland. This article is an open access article distributed under the terms and conditions of the Creative Commons Attribution (CC BY) license (https:// creativecommons.org/licenses/by/ $4.0 /)$.

\author{
Department of Engineering and Technology, Hafiz Hayat Campus Gujrat, University of Gujrat, \\ Gujrat 50700, Pakistan; si@uog.edu.pk (S.I.); EMAI@gmail.com (A.A.) \\ * Correspondence: ajmalghuman023@gmail.com \\ † Presented at the 1st International Conference on Energy, Power and Environment, Gujrat, Pakistan, \\ 11-12 November 2021.
}

\begin{abstract}
This paper proposes a solar-powered resonant inverter fed a high-voltage DC power supply. In this converter, switching loss is controlled through zero-voltage switching and zerocurrent switching. This converter comprises a solar panel, boost converter, full-bridge LLC resonant tank, power transformer, and rectifier circuit. All power switches are operated with an interleaved switching cycle to ensure equal power flow from the tank. This proposed converter is designed to produce a regulated $19.5 \mathrm{KV}$ at output, with an input voltage range of 300-350 V. The proposed converter was simulated in PSpice to verify the results.
\end{abstract}

Keywords: resonant power convertors; DC-DC power convertors; photovoltaic power systems; rectifier; power transformers

\section{Introduction}

Resonant DC/DC converters are a circuit topology which convert one specific level of voltage to another voltage level, which is either below or above the applied level. Resonant converters have the main benefits of attaining zero-voltage (ZVST) or zerocurrent switching (ZCST) [1], which means that either voltage level across switches or the current through them during switching transitions must be zero. Resonant converters have the drawback of larger ripples at resonance frequency, thus increasing the stress on components and increasing the conduction losses, which may hamper the benefits of soft switching [2]. There are various types of topologies used in industry, including series-resonant converters (SRCs), parallel-resonant converters (PRCs) and series-parallel converters (SPRCs) or LLCs [2]. LLCs have received considerable research interest, and have been used in various application [3]. The initialism "SRC" stands for series resonant converter. As its name indicates, in it, a resonant capacitor and a resonant inductor are inserted in series with the output load resistance. Notably, series resonant converters are not the best candidates when the load at the output is minimal because its gain curve is flat at zero or I no-load conditions, so it cannot be regulated properly in light-load conditions [4]. Another problem associated with this topology is that it has high losses at the switching-off transition when the system is operating above resonance. Therefore, it is not suitable for large ranges of input voltages and load variations. PRC stands for parallelresonant converter [5], which also has two components in its resonance tank; however, as its name describes, it has a resonance inductor in series with a resonance capacitor which is at parallel with the rectifier stage. The resistance at output of this topology has huge effects on its peak gain, and this occurs at frequencies lower than the resonance frequency, which is why its peak frequency is lower when the load is heavier at output. The peak value can be more or less than unity; therefore, it is most appropriate for wider input voltage applications. However, the peak parallel resonance converter frequency is not stable and heavily depends on outer load and tank parameters, which is why when the 
load increases, gain and peak frequency will decrease. Series-parallel resonant converters (SPRCs) [6] are a combination of series and parallel connections of resonance capacitors and inductors. LLCs have perks of both series resonant converters and parallel resonant converter, which can be summarized as: operation at higher frequencies with minute losses by using soft switching techniques (ZVST and ZCST) [7-10] for obtaining enhanced density and enhanced efficiency, and this converter is suitable and most appropriate for handling wide variations in input voltage and load, and has the ability to efficiently produce output voltages at a constant level.

\section{Proposed Converter}

The proposed circuit is presented by dividing the circuit into two parts because the said circuit is the combination of two converters: (1) a boost converter and (2) an LLC resonant converter. Figure 1 visualizes the circuit diagram of the proposed research, consisting of solar panels (Vin), four full-bridge inverters (S1, S2, S3 and S4) in each cascade circuit, three LLC resonant tanks (capacitor, Cr; resonant inductor, Lr; and magnetizing inductor, Lm), three transformers (T), four rectifier circuits (D1, D2, D3, and D4) in each cascade circuit, and output capacitor Co and output resistance Ro.

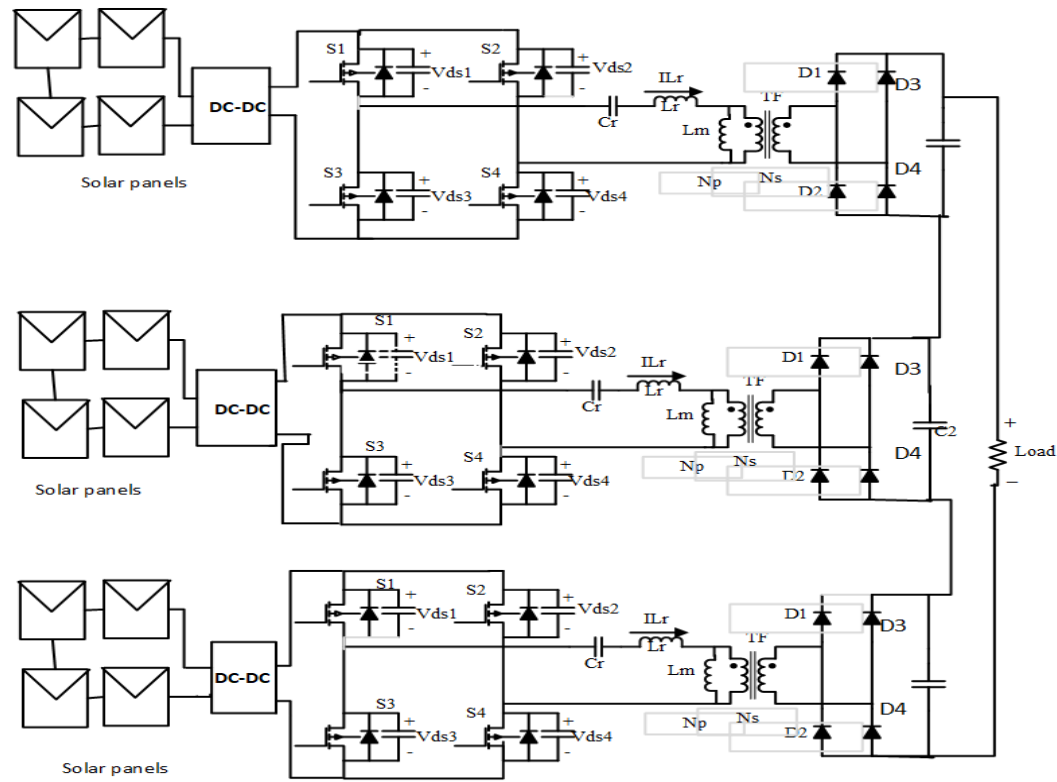

Figure 1. Solar powered resonant inverter fed a high-voltage DC power supply.

This proposed circuit is basically a combination of full-bridge converters and alternatively fed with a 50\% duty cycle by switches S1, S4 and S2, S3, respectively, thus enabling double the power flow from source to load in a single cycle.

The boost converter is a switching converter working on the periodic operation of electronic switching. It produces an output which is greater than the supply voltage. Figure 2a shows the working of the abovementioned converter when switch S2 is closed and switch $\mathrm{S} 1$ is opened. In this condition, the MOSFET is ON and the inductor L boost stores energy in the form of a magnetic field; in the same phase, the diode of switch $\mathrm{S} 1$ becomes reverse-biased, and the resonant tank is supplied by capacitor $\mathrm{C}_{\mathrm{bus}}$. The LLC resonant converter is a combination of series and parallel connections of resonance capacitors and inductors. It is also called an LCC converter because its resonant tank consists of two capacitors and one inductor (Figure $2 b$ ). 


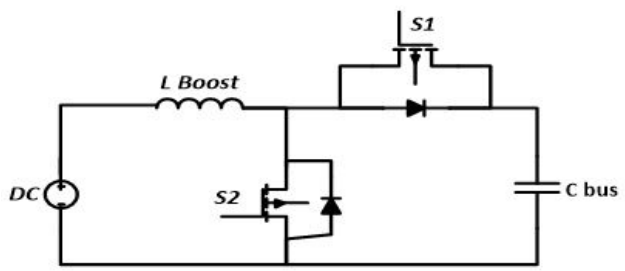

(a)

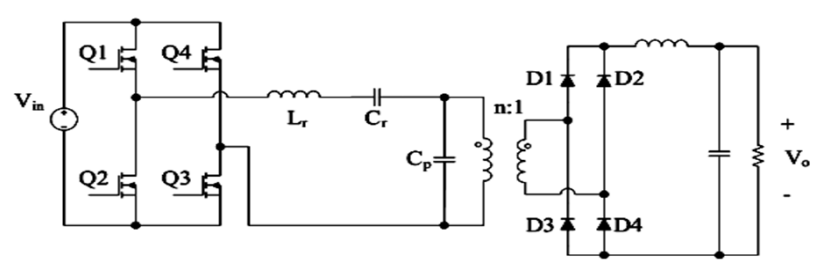

(b)

Figure 2. (a) Equivalent circuit of a boost converter. (b) LLC resonant converter.

\section{Results}

The result of the PSpice simulation with the components in Table 1 are depicted in Figures $3-5$.

Table 1. Components and parameters of the simulation circuits.

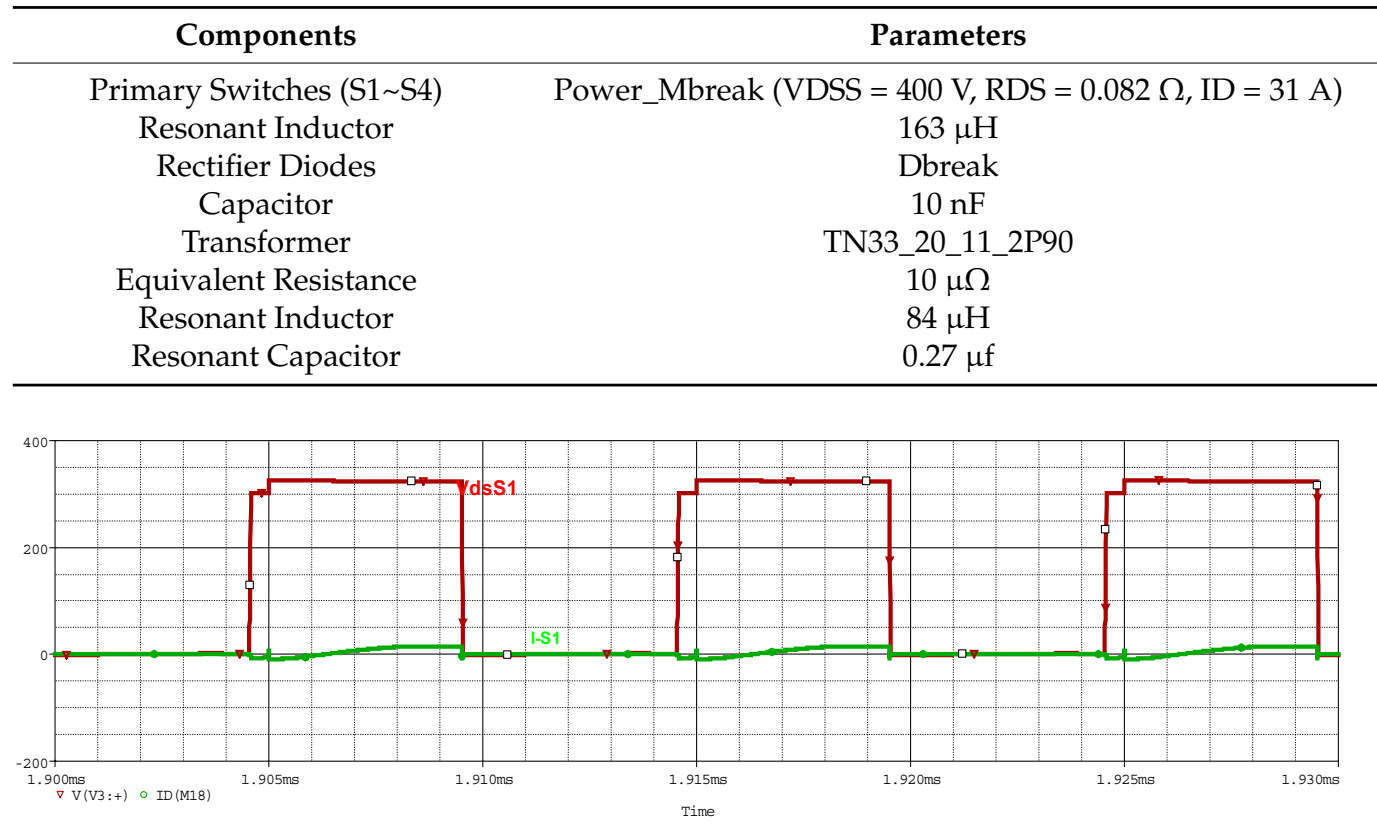

Figure 3. Simulated waveform of voltage at drain to source and current of MOSFET S1.

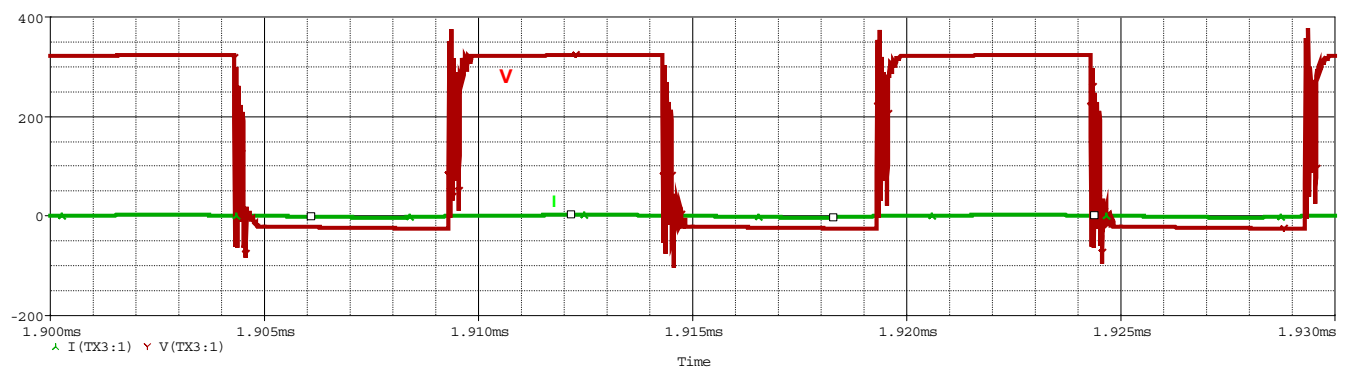

Figure 4. Simulated waveform of tank voltage and current $(300 \mathrm{~V}, 100 \mathrm{kHz})$. 


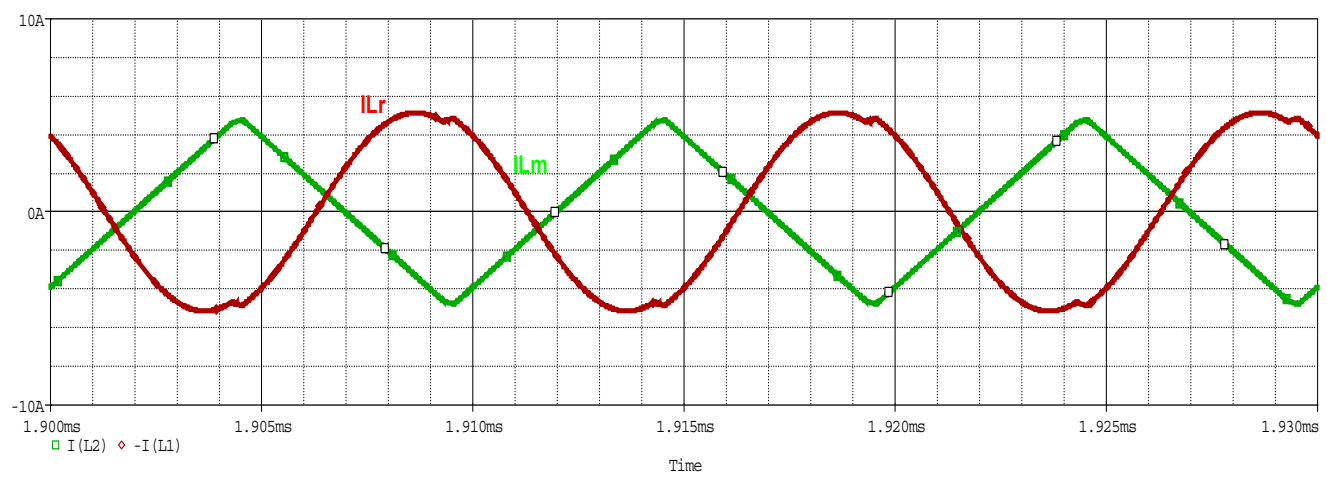

Figure 5. Combined effect of resonant inductor current and magnetizing current.

The voltage at drain to source and current of MOSFET are depicted in Figure 3, where the input voltage is $300 \mathrm{~V}$, the frequency of MOSFET is $100 \mathrm{kHz}$, and the output voltage is $19.5 \mathrm{kV}$. We considered the minimum input voltage applied to the converter as $300 \mathrm{~V}$, and it produced $19.5 \mathrm{kV}$ at a frequency of MOSFETs $100 \mathrm{kHz}$. In this condition, at zero current, the switches turned on and off, and at zero voltage, the power switches turned on as well.

In Figure 4, the simulated waveform of current and voltage of resonant tank are shown. The filled line waveform indicates voltage, and the dotted line waveform shows the current. The input voltage and frequency are the same, i.e., $(300 \mathrm{~V}, 100 \mathrm{kHz})$ and producing an overall output voltage of $19,500 \mathrm{~V}$. From this, we can conclude that this converter has high gain because it produces $19,500 \mathrm{~V}$ at a minimum input of $300 \mathrm{~V}$.

Figure 5 shows the result of a combined resonant inductor (Ir) and magnetizing current (Im). The value of Ir is nearly sinusoidal when the operating frequency is equivalent to the resonance frequency. The magnetizing current (Im) starts rising linearly in the period ( $\mathrm{t} 0-\mathrm{t} 1)$, approaching its peak value.

\section{Conclusions}

This research will help the energy sector to overcome energy crises by using solar power, and addresses the issue of low output from solar panels, which can be directly used in high-voltage applications through this converter. It has higher efficiency, less stress on components, and low EMI. The proposed circuit consists of four major parts: a boost converter, which is used to double the input value; a full bridge; a resonant tank; and a rectifier. The input of this circuit was 300 to $350 \mathrm{~V}$, and the output was $19.5 \mathrm{kV}$.

Institutional Review Board Statement: Not applicable.

Informed Consent Statement: Not applicable.

Data Availability Statement: Not applicable.

\section{References}

1. Iqbal, S. Double LLC resonant tanks based DC-DC converter with integrated dual transformers for PV power systems. In Proceedings of the 2016 IEEE Power and Energy Conference at Illinois (PECI 2016), Urbana, IL, USA, 19-20 February 2016. [CrossRef]

2. Samsudin, N.A.; Iqbal, S.; Taib, S. LLC resonant high-voltage DC-DC converter with voltage multiplier rectifier. In Proceedings of the 5th IEEE International Conference on Control System, Computing and Engineering (ICCSCE 2015), Penang, Malaysia, 27-29 November 2015; pp. 508-513. [CrossRef]

3. Bhat, A.K.S. Analysis and Design of LCL-Type Series Resonant Converter. IEEE Trans. Ind. Electron. 1994, 41, 118-124. [CrossRef]

4. Lee, S.S.; Iqbal, S.; Jamil, M.K.M. A new ZCS series resonant high-voltage DC power supply. In Proceedings of the PECon 2012-2012 IEEE International Conference on Power and Energy, Kota Kinabalu, Malaysia, 2-5 December 2012; pp. 44-48. [CrossRef]

5. Mierczuk, M.K.K.; Thirunarayan, N.; Wang, S. Analysis of series-parallel resonant converter. IEEE Trans. Aerosp. Electron. Syst. 1993, 29, 88-99. [CrossRef]

6. Lu, B.; Liu, W.; Liang, Y.; Lee, F.C.; van Wyk, J.D. Optimal design methodology for LLC resonant converter. In Proceedings of the IEEE Applied Power Electronics Conference and Exposition-APEC, Dallas, TX, USA, 19-23 March 2006; pp. 533-538. [CrossRef] 
7. Fang, X. Analysis and Design Optimization of Resonant Dc-dc Converters. Electronic Theses and Dissertations. 2012. Available online: https: / / stars.library.ucf.edu/etd/2125 (accessed on 22 February 2020).

8. Azura, N.; Iqbal, S.; Taib, S. LLC resonant DC-DC converter for high voltage applications. In Proceedings of the 2014 IEEE Conference on Energy Conversion (CENCON 2014), Johor Bahru, Malaysia, 13-14 October 2014; pp. 90-95. [CrossRef]

9. Tseng, S.Y.; Lin, H.C.; Chang, Y.D.; Peng, S.T.; Fan, S.Y. $10 \mathrm{kV}$ high voltage generator with LLC resonant circuit for sterilizing microbe applications. In Proceedings of the IEEE Applied Power Electronics Conference and Exposition-APEC, Washington, DC, USA, 15-19 February 2009; Volume 4, pp. 1641-1646. [CrossRef]

10. Tseng, S.Y.; Wu, T.F.; Chen, Y.M. Wide pulse combined with narrow-pulse generator for food sterilization. IEEE Trans. Ind. Electron. 2008, 55, 741-748. [CrossRef] 